\title{
Videojuegos: realidad que desborda los límites. Acercamiento teórico de posibles modificaciones cognitivas y funcionales en jóvenes ${ }^{*}$
}

\author{
María Daniela Salcedo Mejía* \\ Recibido: abril 23 de 2014 • Evaluado: mayo 27 de 2014
}

Aceptado: junio 18 de 2014

\section{Resumen}

Se reconoce la importancia de entender mejor los posibles efectos que tiene la tecnología en la vida cotidiana de niños y jóvenes, como en el caso del uso de los videojuegos. Se hace necesario dar cuenta de los últimos hallazgos investigativos que permitan esclarecer cómo y por qué los videojuegos aportan o no al individuo, con el fin de dar inicio a lo que será la acogida y la transformación del uso de este tipo de tecnología en pro de un mejor desarrollo en el campo físico y cognitivo.

En el presente artículo, se presenta un acercamiento teórico a los videojuegos y a sus posibles efectos en las capacidades cognitivas y funcionales, seguido de una reflexión de su posible uso.

Palabras clave: videojuegos, capacidades cognitivas, capacidades funcionales, jóvenes.

"El presente artículo es resultado del trabajo de grado titulado "Los videojuegos como modificadores de los patrones cognitivos y funcionales en jóvenes de 18 a 23 años", investigación que terminó en el primer semestre del 2014 tras una duración de año y medio. El trabajo estuvo vinculado al grupo de investigación Gicaeds, de la línea de investigación en Fisiología del Ejercicio y Entrenamiento Deportivo. El director fue el docente Jhon Fredy Ramírez Villada. Se agradece y reconoce la colaboración de Héctor Iván Hernández Martínez como parte fundamental del equipo de trabajo.

"* Profesional en Cultura Física, Deporte y Recreación, Universidad Santo Tomás. Correo:mariamejia@usantotomas.edu.co 


\section{Video Games: reality beyond the limits. Theoretical approach of possible cognitive and functional alterations in young}

\section{Abstract}

Recognizing the importance of a greater understanding of the possible effects of technology in the daily lives of children and youth, as it is the specific case of the use of video games; reaches a breakpoint, where it is necessary to account for recent findings at the research level, so that you can clarify how and why video games contribute or not the individual in its development pipeline, in order to to begin what will be the reception and transformation of using this type of technology for a better development in the physical realm as cognitive.

In the development of this article a theoretical approach of video games to their potential effects on cognitive and functional abilities, followed by a subjective reflection of the possible use of them is presented.

Keywords: Games, cognitive and functional abilities. 


\section{Introducción}

Los videojuegos se han convertido, más que en una simple distracción o "un simple pasatiempo", en la actividad predilecta de algunos niños y jóvenes. A diferencia de actividades como ir a cine, ir a un centro comercial o ver televisión, los videojuegos forman parte de su realidad. Esto los convierte en una problemática que atenta contra su desarrollo, puesto que, sin pensar, están dedicando gran parte de sus días a dicha práctica. Familiares y amigos concluyen que los videojuegos generan sedentarismo y, en ocasiones, comportamientos agresivos debido a sus contenidos.

Por lo tanto, en el presente artículo se expresan diferentes puntos de vista de los investigadores acerca del uso de este tipo de tecnología, así como las posibles alteraciones a nivel cognitivo y funcional que pueden generarse a partir de su práctica. Se concluye que la tecnología puede volverse un factor de apoyo para el desarrollo de los niños y jóvenes, y se corrobora en este sentido que no es la tecnología lo que daña al hombre, sino que son los individuos quienes distorsionan y modifican sus beneficios debido al uso inadecuado que le dan.

\section{Los videojuegos: una realidad que desborda los límites}

Como ya se mencionó, los videojuegos se han convertido en una de las actividades predilectas de niños y jóvenes. En su estudio, Trigo (2010) hace un análisis acerca del surgimiento del sedentarismo y afirma que debido a la revolución tecnológica producida en el siglo XX, los seres humanos son cada vez más sedentarios. Pero si bien Trigo (2010) habla así acerca de la revolución tecnológica, se debe tener en cuenta que esta no solo ha sido “atacada", sino que también en los últimos años se le han encontrado múltiples usos a la tecnología. Investigaciones como la de Revuelta y González (2009) han demostrado que los videojuegos fomentan una ayuda especial en el tratamiento y la mejora de problemas educativos, físicos y psicológicos, además de que aportan al entrenamiento de todo tipo de habilidades.

Lo anterior es prueba de un nuevo panorama que acoge el análisis del avance tecnológico, específicamente en relación con los videojuegos, en el 
cual no es la tecnología el enemigo, sino que se puede convertir en un medio para conseguir un fin determinado, ya sea en el campo educativo, terapéutico, psicológico o físico.

Así mismo, Epstein y colaboradores (2007) identifican que los videojuegos interactivos se convierten en una alternativa popular de actividad física en jóvenes y adolescentes (se destacan el baile y el ciclismo), dado que uno de los avances en este tipo de videojuegos es el requerimiento de actividad física al combinar ejercicio y entretenimiento.

De otra parte, Revuelta y Guerra (2012) afirman que los videojuegos son un medio educativo con el cual las personas se motivan, construyen aprendizajes significativos, adquieren contenidos en múltiples campos, adquieren coordinación y competitividad, y además fortalecen habilidades psicomotrices como reflejos y percepción, las cuales cumplen un papel importante en el desarrollo de la persona.

$\mathrm{Y}$ es justamente bajo estos criterios que se podría iniciar una inclusión de los videojuegos en los diferentes ámbitos formativos, como medio desarrollador de las habilidades y capacidades que el joven necesita para su vida, lo cual ya se está reflejando en la realidad de algunas escuelas formativas.

A este respecto, Pimienta (2010), en su estudio "La educación primaria en el Reino Unido y España”, comprueba que un creciente número de escuelas está incorporando las tecnologías de la información y la comunicación (TIC) no solo como asignatura en el currículum, sino también como una manera de hacer que el resto de las lecciones sean más ligeras y atractivas para los alumnos; y si bien la tecnología ayuda en distintos campos del desarrollo humano, se destaca el uso de videojuegos en la clase de educación física, atribuyéndole el hecho de la motivación del estudiante (Pimienta, 2010).

De igual manera, cabe rescatar que los beneficios de la actividad realizada por medio de los videojuegos es un tema muy debatido por varios autores. Es el caso de Marín (2011), quien en su estudio esclarece el uso beneficioso de los videojuegos, pero también lo lleva al punto de quiebre, afirmando que no todos los videojuegos sirven para mejorar o potenciar todas las dimensiones del ser humano. Por el contrario, Marín (2011) establece una serie de beneficios relacionados con solo una clase de juegos. Esto se expresa en la siguiente clasificación:

- Los videojuegos de tipo arcade: potencian el desarrollo psicomotor y la orientación espacial. 
- Los videojuegos de deportes: ayudan a desarrollar habilidades psicomotoras y conocimiento de las reglas en los deportes.

- Los videojuegos de aventura y de rol: inicia la mejora del conocimiento de diferentes temáticas.

- Los videojuegos tipo simuladores: ayudan a controlar la tensión y a desarrollar la imaginación.

- Los videojuegos de estrategia: permiten administrar recursos normalmente escasos.

De acuerdo con lo planteado por Marín (2011), y teniendo en cuenta la clasificación de los videojuegos, se puede afirmar que existe una relación directa entre la tecnología y el individuo. En apoyo a lo dicho por Marín, Castillo y colaboradores (2012) plantean que los videojuegos deportivos son actividades que mezclan múltiples aspectos de los juegos y el deporte, como el entrenamiento, el desarrollo físico, el estímulo psicológico y la competencia, mejorando el buen desarrollo de habilidades psicomotoras y el adecuado conocimiento de las reglas de los deportes practicados.

Así mismo, Alfageme y Sánchez (2002) plantean que el uso de videojuegos mejora y fortalece tanto la parte motriz como la cognitiva, además de desarrollar y afianzar habilidades sociales como la solución adecuada de problemas de la vida diaria y la eficacia en la toma de decisiones. Esto, sin lugar a dudas, es un concepto que comulga directamente con lo expuesto por Marín (2011) y Castillo et al. (2012), entre otros autores.

A diferencia de estas posturas, Ortega (2010) manifiesta que el uso inadecuado de la videoconsola Wii puede causar lesiones en el tren superior. Sin embargo, Abalo (2012), al igual que Ortega (2010), concluye que la práctica de actividad física empleando una consola puede ser una alternativa al sedentarismo, siempre que se realice siguiendo las recomendaciones básicas: ropa y calzado adecuado, calentamiento previo, mantener la zona de juego libre de obstáculos, una intensidad de juego adecuada a cada participante, no exceder el tiempo de práctica, realizar estiramientos al terminar el juego, etc.

Ahora bien, existen algunos estudios en los que el interés se centra específicamente en las alteraciones de los patrones cognitivos. Entre ellos se resalta el estudio de Baudis y Derain (2013), titulado L'enfants et les écrans (Los niños y las pantallas), en el que se concluye que el uso de las 
videoconsolas con videojuegos de acción pueden mejorar la atención visual, simultánea y selectiva.

De otro lado, Moral (2010) afirma que existe una alteración dada por algunos videojuegos, que se caracteriza por el desarrollo de las inteligencias múltiples; y González y colaboradores (2007) afirman que los videojuegos permiten el desarrollo de nuevas tendencias de aprendizaje.

Autores como Rossell y colaboradores (2007) aseguran que el uso de los videojuegos en la juventud crea dependencia, haciendo que los jóvenes se alejen de la realidad para entrar en una "realidad virtual", lo cual se ve reflejado en sus resultados académicos.

$\mathrm{Al}$ igual que estos últimos autores, Machargo y colaboradores (2003) afirman que el uso que hacen los jóvenes de esta tecnología no solo es perjudicial, sino que también requiere de la supervisión de un adulto responsable.

\section{Conclusiones}

Con base en lo expresado por los diferentes autores acerca de las posibles alteraciones que puede implicar la práctica de videojuegos por parte de los jóvenes, se concluye que los videojuegos dejan de ser un predictor de consecuencias negativas para convertirse en un factor que podría colaborar en los procesos de desarrollo de algunas capacidades tanto cognitivas como funcionales.

Por lo tanto, es viable apoyar la afirmación dada al inicio del presente artículo: "no es la tecnología la que daña al hombre, sino que es él mismo quien distorsiona su efecto por el mal uso le da". En atención a ello, y como profesionales de Cultura Física, Deporte y Recreación, debemos dar un sí al progreso y hacer de la tecnología un medio que aporte a la mejora de la calidad de vida de los diferentes grupos etarios, ya que si bien para un adulto es atractivo realizar ciertas actividades al aire libre, los niños y jóvenes se encuentran en una etapa en la que se sienten atraídos por los videojuegos y por la interacción con este tipo de medio virtual.

Entonces si se induce en los jóvenes una actividad que los aleja de su centro de diversión, los aspectos emocionales jugarán un papel crucial en la efectividad de las actividades propuestas para el desarrollo de las diversas capacidades; pero si se les propone desarrollar las mismas capacidades 
haciendo uso de su centro de diversión, será posible captar su atención en un porcentaje más alto.

Por último, la presente reflexión evidencia la importancia de incluir el uso de la tecnología, en este caso los videojuegos, en los procesos que comprometen el desarrollo de la persona.

\section{Referencias}

Abalo, R. (2012). Videoconsolas: actividad física y lesiones. EFDeportes Revista Digital, 17(167).

Alonqueo, P., \& Rehbein, L. (2008). Usuarios habituales de videojuegos: una aproximación inicial. Última Década, (29), 11-27.

Alfageme, B., \& Sánchez, P. (2002). Aprendiendo habilidades con videojuegos. Revista Científica de Educación y Comunicación, 19, 114-119.

Baudis, D., \& Derain, M. (2012). L'enfants et les écrans. París: Defensoría de los Derechos.

Beltrán-Carrillo, V. J., Valencia-Peris, A., \& Molina-Alventosa, J. P (2011). Los videojuegos activos y la salud de los jóvenes: revisión de la investigación. Revista Internacional de Medicina y Ciencias de la Actividad Física y del Deporte, 11(41), 203-219.

Del Castillo, H., et al. (2012). Desarrollo de competencias a través de los videojuegos deportivos: alfabetización digital e identidad. RED Revista de Educación a Distancia, (33), 1-22.

Epstein, L., Beecher, M., Graf, J., \& Roemmich, J. (2007). Choice of interactive dance and bicycle games in overweight and non-over weight youth. Annals of Behavioral Medicine, 33(2), 124-131.

Frasca, G. (2009). Juego, videojuego y creación de sentido. Una introducción. Comunicación. Revista Internacional de Comunicación Audiovisual, Publicidad y Estudios Culturales, 1(7), 37-44.

Fuentes Trigo, P. (2010). El problema del sedentarismo en la sociedad actual. EFDeportes Revista Digital, 14(141).

García, J., \& Perandones, E. (2009). Videojuegos: mitos y leyendas urbanas sobre la cultura visual adolescente. Ponencia presentada en el III Congreso de Educación de las Artes Visuales, Barcelona, España.

Greenfield, P., \& Zeitlin, E. (1994). Les jeux vidéo comme instruments de socialisation cognitive. Réseaux, 12(67), 33-56. 
González, J., Cabrera, M., \& Gutiérrez, F. (2007). Diseño de videojuegos aplicados a la educación especial. Recuperado de http://aipo.es/articulos/1/12410.pdf

Marín, V. (2011). La perspectiva educativa de los videojuegos, una realidad tangible. Revista de Investigación Educativa. Conectados, 2(2), 60-75.

Machargo, J., Lijan, I., León, M., López, L., \& Martin, M., (2003). Percepción de la influencia del ordenador, de Internet y de los videojuegos por los adolescentes. Anuario de Filosofía, Psicología y Sociología, 6, 159-172.

Moral, M. (2010). Aportaciones y riesgos de los videojuegos. Oviedo: Universidad de Oviedo.

Ortega, O. (2010). Videoconsola Wii: lesiones provocadas por uso inadecuado versus aportaciones al mantenimiento y restauración de la salud. Trances. Revista de Transmisión del Conocimiento Educativo y de la Salud, 2(1), 1-13.

Pimienta, L. (2010) La educación primaria en el Reino Unido y España. Autodidacta. Revista de la Educación en Extremadura, (98). Recuperado de http://www.anpebadajoz.es/autodidacta/autodidacta_archivos/numero_10_archivos/1_p_gomez.pdf .

Revuelta, F., \& Guerra, J. (2012). ¿Qué aprendo con videojuegos? Una perspectiva de meta-aprendizaje del videojugador. RED. Revista de Educación a Distancia, (33), 1-25. Recuperado de https://www.um.es/ead/red/33/revuelta.pdf

Revuelta, F., \& González, L. (2009). Videojuegos y educación. Revista Virtual Facultad de Educación, (2).

Rossell, M., Sánchez, X., Graner, C., \& Beranuy, M. (2007). El adolescente ante las tecnologías de la información y la comunicación: internet, móvil y videojuegos. Revista Papeles del Psicólogo, 28(3), 196-204.

Tejeiro, R., Pelegrina, M., \& Gómez, J. (2009). Efectos psicosociales de los videojuegos. Comunicación. Revista Internacional de Comunicación Audiovisual, Publicidad y Estudios Culturales, 1(12), 235-520. 